\title{
A sedução da etnografia da ciência
}

Renan Springer de Freitas

No final dos anos de 1960, H arold Garfinkel causou algum alvoroço nas ciências sociais ao sustentar, em seu Studies in ethnomethodology, que não há diferença significativa entre a investigação científica e a condução dos mais prosaicos assuntos cotidianos - uma vez que ambas se orientam por um mesmo domínio factual - e propor, a partir daí, uma nova e supostamente mais fundamental agenda de investigação sociológica. A sociologia se pergunta como é possível a ordem social. O ra, raciocina Garfinkel, tal pergunta, ela mesma, só é possível na medida em que se subscreve, irrefletidamente, o pressuposto de senso comum de que há, no mundo, algo passível de ser reconhecido como "ordem social". Como, entretanto, esse pressuposto se estabelece? Por meio de que práticas ou atividades as pessoas, incluindo os cientistas sociais, estabelecem o "fato" de que há, no mundo, algo que possa ser legitimamente chamado de "ordem social" e, mais do que isso, que "ordem social" seja algo passível de "explicação"? Posto que fora de tais atividades sociais não há nada reconhecível como "ordem social", então, examiná-las é al go mais fundamental do que investigar como determinados sistemas de ordem são possíveis. N essa perspectiva, mais fundamental do que investigar, por exemplo, as origens e a viabilidade do capitalismo moderno, seria examinar as atividades por meio das quais se institucionaliza, entre grupos determinados de pessoas - incluindo, como não poderia deixar de ser, os cientistas sociais - a crença de 
1. Ver, por exemplo, 0 modo como Zimmerman e Pollner se pronunciam sobre isso: "por mais que o sociólogo e o leigo divirjam em suas opiniões sobre o modo como umapessoa setorna delinqüente, e se cada um evoca critérioseevidências de natureza bem diferente para corroborar suas versões, eles não vêem, entretanto, qualquer problemaem concordar quehápessoasreconhecíveiscomo delinqüentes e maneiras estruturadas através das quais elas se tornam delinqüentes" (1970, p. 81). que há, no mundo, algo que possa ser legitimamente chamado de "capitalismo moderno"; mais fundamental do que investigar, como o fez D urkheim, as causas sociais do suicídio, seria investigar o modo como, em circunstâncias determinadas, pessoas determinadas estabelecem entre si 0 "fato" de que há, no mundo, algo que possa ser legitimamente chamado de "suicídio", passível, por sua vez, de ser explicado em termos de al go que possa ser legitimamente chamado de "causas sociais", e assim por diante.

0 alvoroço que tudo isso provocou teve um fim quando se contrastou a proposta, extremamente ousada, de atingir um nível mais profundo da realidade social via investigação dos pressupostos que as análises sociológicas deixam sem exame com os resultados, extremamente tímidos, a que tal investigação se mostrou capaz de conduzir. Considere-se o caso dos estudos sobre criminalidade, um tema particularmente caro aos etnometodólogos. O s sociólogos, de um modo geral, perguntam quais são as causas sociais desse fenômeno. Os etnometodólogos objetam. Para formular essa pergunta, eles dizem, é necessário pressupor, sem nenhum exame crítico, que há, no mundo, algo intersubjetivamente reconhecível como "crime". Assim, mais fundamental do que investigar as causas da criminalidade é investigar o modo como, em circunstâncias determinadas, tal reconhecimento intersubjetivamente partilhado se dá. Nos anos que se seguiram à publicação de Studies in ethnomethodology, um grande número de estudos empíricos abandonou qualquer pretensão de explicar causal mente a criminalidade e embarcou nessa linha de investigação. Fundamentalmente, isso conduziu a descrições de como relatos testemunhais, dossiês, fotografias, laudos periciais etc. adquirem, em delegacias e/ ou tribunais, o status de "evidência documental", e dos processos por meio dos quais se torna possível, nesses mesmos locais, acreditar que "crime", "ato criminoso", "delito" etc. sejam fatos objetivos, independentes das atividades sociais que viabilizam sua emergência como tais em circunstâncias particulares.

Essas descrições cumprem bem sua meta: tornar explícitos certos pressupostos de senso comum que ambos, o sociólogo e o leigo, irrefletidamente subscrevem em suas respectivas al egações de conhecimento ${ }^{1}$. Entretanto, seguindo a conhecida terminologia de Lakatos, eu diria que elas constituem um programa de pesquisa degenerativo, pois não ensejam investigações adicionais. Q uando acabamos de ler essas descrições, não nos resta muito mais a fazer senão balançar a cabeça e exclamar para nós próprios: "interessante!".

A voga recente de estudos etnográficos sobre a ciência parece-me, sobretudo, uma reedição dessa pretensão etnometodológica de atingir camadas, 
por assim dizer, mais profundas do conhecimento via descrição de práticas sociais. Esses estudos consistem principalmenteem um esforço para substituir a agen da tradicional de investigações da sociologia da ciência - o exame das condições sócio-históricas de institucionalização da ciência - por uma agenda supostamente mais fundamental ${ }^{2}$. Essa nova agenda consistiria basicamente no estudo da "ciência em construção" (sciencein-themaking), em oposição à ciência já estabelecida como corpo de conhecimento, da qual a sociologia da ciência tradicionalmente se ocupa. Em al guns casos, a fascinação pela science in-the making traduziu-se no exame dos modos pelos quais se estabelecem, na comunidade científica, acordos tácitos sobre o que conta como "fato", "evidência", "erro", "replicação", "problema científico" etc. ${ }^{3}$. Em outros, no exame das estratégias utilizadas pelos cientistas para convencer seus pares - ou a sociedade de um modo geral - da validade de suas alegações de conhecimento; no exame dos modos pelos quais os cientistas mobilizam interesses dos mais diversos segmentos da sociedade em favor de seus próprios interesses4.

Essa nova agenda não deixa de ter seu apelo, mas, como se costuma dizer, a prova do pudim está em comêlo. A quê esse foco, supostamente mais fundamental, na science in-themaking conduziu? Antes de responder, discutiremos o que o tornou possível.

A condição de possibilidade, por assim dizer, do foco na sciencein-the making é a recusa sistemática em tomar conhecimento do debate - que começou a ganhar corpo a partir dos anos de 1960 com o trabalho seminal deT homas Kuhn, A estrutura das revoluções científicas, e teve grande incremento com a publicação, em meados dos anos de 1970, do controvertido livro C ontra o método, de Paul Feyerabend - sobre a pertinência da dicotomia contexto da descoberta/contexto da justificação ${ }^{5}$.

Postular tal dicotomia é postular a existência de duas agendas independentes de indagação. A primeira diz respeito, basicamente, ao processo por meio do qual uma hipótese ou teoria foi gerada. $N$ esse plano, chamado de "contexto da descoberta", apresentam-se indagações do tipo: como ocorreu a N ewton as idéias de "força gravitacional" e "ação à distância"? Q ual foi o papel, nesse processo, de suas crenças religiosas e do meio sociocultural em que viveu? Como a sociedade inglesa do século XVII recebeu essas noções? A que estratégias argumentativas $\mathrm{N}$ ewton recorreu para rebater
2. Considere-se, a propósito, o que se lê na introdução de um livro paradigmático nessa área: "O esforço que este livro requer é um descarrilamento inicial damentedostrilhos do senso comum. N osso ambiente cultural - 0 mundo cotidiano - tem que ser transformado em um lugar estranho para que possamos entender que o caráter ordenado quese atribui a ele é uma realização humana notável emisteriosa" (Collins, 1992, p. 1). Comparese tal afirmação com o exemplo da nota anterior.

3. Refiro-me, aqui, aos auto-intitulados "socioconstrutivistas" ou "sociólogos do conhecimento científico".

4. Refiro-meaqui àchamada "teoria do atorrede", de Bruno Latour.

5. Embora essas expressõessejam relativamente recentes, tendo sido introduzidas por $\mathrm{H}$ ans Reichenbach nos anos de1930, a idéia de que discutir a pertinêncialógica de uma teoria ereconstruir o processo por meio do qual ela foi ge rada são exercícios que não se sobrepõem remonta ao início do sé 
culo XIX. Assim, já em 1830, H erschel, em seu A preliminary discourse on the study of natural philosophy, afirmava que no estudo da natureza não devemos ser escrupulosos a respeito de como se alcança um conhecimento de leis e teorias, desde que possamos verificálascuidadosamente, uma vezque tenham sido formuladas. H ojenão diríamos "verificá-las", mas sim "testá-las". Para uma discussão recente acerca da distinção contexto dadescoberta/contexto da justificação, ver 0 trabalho deH oyningenHuene (1987). seus oponentes? Q uão bem-sucedido ele foi em seu esforço de convencer seus pares da validade de suas al egações de conhecimento? Em que medida o sucesso de N ewton em convencer seus pares dependeu de resultados experimentais? A segunda agenda de indagação diz respeito ao processo por meio do qual a pertinência e, por assim dizer, a importância científica da hipótese ou teoria gerada pode ser aferida. N esse plano, o do chamado "contexto da justificação", apresentam-se indagações do tipo: como testar a validade da teoria newtoniana da gravitação universal? Q ue resultados experimentais seriam logi camente incompatíveis com essa teoria? Q ue problemas ela (independentemente do que $\mathrm{N}$ ewton pudesse pensar a respeito) soluciona? Q ue problemas é incapaz de resolver? Q ue ramificações tem? Q ue problemas (independentemente do que N ewton pudesse pensar a respeito) foram suscitados a partir dela? Q ue relação há entre essa teoria e, digamos, a teoria cartesiana dos vórtices? Q ue relação há entre essa teoria e a teoria da relatividade geral proposta por Einstein? Teria a teoria newtoniana aberto o caminho para a einsteiniana? Se sim, em que sentido?

N ota-se que, nos marcos dessa dicotomia, o conhecimento científico desfruta de uma autonomia em relação às circunstâncias sociopsicológicas nas quais é produzido e aceito (ou, se preferir, rejeitado). Posto de outra forma, a referida dicotomia encoraja-nos a averiguar, à margem de qualquer consideração a respeito de circunstâncias sociopsicológicas, se uma determinada teoria constitui ou não um avanço genuíno de conhecimento em relação a al guma outra e/ou uma contribuição significativa quer para a emergência, quer para o desenvolvimento, de algum corpo de conhecimento. Tanto Kuhn como Feyerabend se notabilizaram por se contrapor a tal pretensão. Ambos se empenharam em mostrar que é impossível compreender tanto a natureza do conhecimento científico como o modo pelo qual esse conhecimento avança à margem de uma investigação do processo sociopsicológico que lhe deu origem. Q uando, entretanto, se trata de apontar o que há de tão relevante nesse processo, eles tomam caminhos bem distintos.

Kuhn aponta a leal dade dos cientistas a alguma tradição, sem a qual, ele diz, é possível que haja "áreas de estudos", mas, não, ciência propriamente dita. Já no primeiro capítulo de A estrutura das revoluções científicas ele deixa isso claro ao explicar que a óptica física anterior a $\mathrm{N}$ ewton não chegava a ser uma ciência: concluir que, embora os estudiosos dessa área fossem cientistas, o resultado líquido 
de suas atividades foi algo menos que ciência. Por não ser obrigado a assumir um corpo qualquer de crenças comuns, cada autor de Ó ptica Física sentia-se forçado a construir novamente seu campo de estudos desde os fundamentos. A escolha das observações e experiências que sustentavam tal reconstrução era relativamente livre. N ão havia qualquer conjunto-padrão de métodos ou de fenômenos que todos os estudiosos da Ó ptica se sentissem forçados a empregar e explicar (Kuhn, 1982, p. 33, grifos meus).

Feyerabend, em claro contraste, aponta todo um conjunto de práticas maquiavélicas - como amoldar evidências a "idéias caprichosas", recorrer a procedimentos ad hoc para afastar ou eliminar dificuldades, ou lançar mão de argumentos ad hominem - peculiares à atividade científica. Sem elas, defende Feyerabend, não haveria ciência tal como hoje a conhecemos: não teria ocorrido a invenção do atomismo na Antigüidade, nem a revolução coperniciana, nem o surgimento do atomismo moderno (teoria cinética; teoria da dispersão, estereoquímica, teoria quântica), nem o aparecimento gradual da teoria ondulatória da luz, para citar apenas al guns poucos exemplos. N ão importa, argumenta Feyerabend, ecoando Einstein, que aos olhos de um guardião da racionalidade científica tais práticas soem como 0 mais "inescrupuloso oportunismo", porque sem elas simplesmente não há ciência. M aquiavel pontificou que nas ações dos homens contra as quais não há tribunal a que recorrer o que conta são os fins. Talvez o essencial da "epistemologia anárquica" de Feyerabend esteja em transpor essa máxima para a filosofia da ciência. Afinal, ele diria, o que pode haver de errado em violar, de forma sistemática, todo e qualquer cânone metodológico racionalmente prescrito se a história da ciência mostra que tal violação conduziu o empreendimento científico a resultados auspiciosos? Se a história recomenda procedimentos que os epistemólogos condenam, tanto pior para esses últimos.

Admitindo-se que tanto Kuhn quanto Feyerabend tenham razão no que toca às suas considerações sobre a importância, respectivamente, da fidelidade a uma tradição e do "inescrupuloso oportunismo" peculiar ao comportamento dos cientistas, e que as diferenças entre eles possam ser, no fim das contas, de al guma forma reconciliadas, constituiriam os argumentos acima apresentados uma boa razão para rejeitar a dicotomia contexto da descoberta/contexto da justificação - e, portanto, a tese de que 0 conhecimento científico desfruta de uma autonomia em relação ao processo sociopsicológico que lhe deu origem? 
Iniciemos por Kuhn, retomando seu exemplo da óptica anterior a N ewton. A dicotomia em questão nos compele a averiguar, à margem de qualquer consideração de ordem sociopsicológica, se o conhecimento que essa óptica produziu é válido e se teve ou não alguma importância para o desenvolvimento posterior dafísica. Se éassim, então, mostrar a impertinência da referida dicotomia é uma questão de mostrar a inviabilidade de tal exercício. É uma questão de mostrar que à margem de considerações de ordem sociopsicológica nada pode ser dito sobre a cientificidade da referida ó ptica. Pois foi exatamente tal exercício que Kuhn se prontificou a fazer. Ele se ancorou exclusivamente em uma consideração de ordem sociopsicológica - a de que os estudiosos da óptica não eram obrigados a partilhar um "conjunto qualquer" de crenças comuns - para concluir que o "resultado líquido" das atividades desses estudiosos foi "al go menos que ciência".

Entretanto, falta ainda responder (ou, dito de outra forma, a dicotomia contexto da descoberta/contexto da justificação nos compele a perguntar) se tal "resultado líquido", mesmo sendo "algo menos que ciência", teve, como corpo de conhecimento, al guma relevância para o desenvolvimento posterior da física. $\mathrm{N}$ ão sei se a resposta que Kuhn tem a oferecer é um apriorístico "não" ou simplesmente o silêncio. 0 silêncio seria concessão grande demais à dicotomia da qual quer se livrar. 0 "não" apriorístico, por outro lado, implicaria enclausurar definitivamente a óptica anterior a N ewton no século XVII, isto é, proibiria de antemão qualquer tentativa de averiguar se corpos de conhecimento produzidos em tempos passados têm alguma relevância para corpos de conhecimento produzidos em algum tempo posterior, quer isso signifique um passado menos remoto, o presen-

6. Ao contrário deKuhn, não penso que o empe nho em preservar a "integridade histórica" de uma ciência seja um mérito, nem umacaracterística da historiogra fia da ciência de Koyré. 0 grande mérito dessa extraordinária historiografia está em ter féto deuma reflexão sobreo queéumaboaciênciao seu carro-chefe. Ver Freitas (2004). te ou mesmo o futuro. $\mathrm{N}$ a verdade, a perspectiva de Kuhn implica, inapelavelmente, tal confinamento. Já nas primeiras páginas de A estrutura das revoluções científicas, ele elogia a historiografia da ciência de Alexandre Koyré por zelar pela "integridade histórica" das ciências sobre as quais se debruça. Essa historiografia, ele diz, apresenta a ciência a partir de sua própria época, em vez "de procurar as contribuições permanentes de uma ciência mais antiga para nossa perspectiva privilegiada" ${ }^{\prime}$. Em vez, por exemplo, deinvestigar a relação entre as concepções de G alileu e as da ciência moderna, ela investiga a relação entre as concepções de $G$ al ileu e aquelas partilhadas por seu grupo, isto é, seus professores, contemporâneos e sucessores imediatos na ciência (cf. Kuhn, 1982, p. 22). O ra, por que não podemos perguntar pela relação entreas concepções de G alileu eas da ciência moderna? Por que devemos, de antemão, enclausurar o pensamento de $G$ alileu 
no século XVIII? Receio queK uhn não tenha outra resposta a oferecer senão dizer que tais perguntas só fazem sentido nos marcos de uma historiografia da ciência que se ancore no conceito de "desenvolvimento-por-acumulação", ela própria tributária da dicotomia contexto da descoberta/contexto da justificação, e que, por não considerar tal dicotomia pertinente, não poderia se ocupar dessas perguntas. Para Kuhn, ao quetudo indica, o único meio de rejeitar a visão, sem dúvida equivocada, de que a ciência avança por meio da acumulação de descobertas e verdades definitivamente estabelecidas é zelar pela "integridade histórica" da ciência do passado.

$H$ á, entretanto, outro filósofo da ciência que, embora, como Kuhn, se apresente como um ferrenho adversário da dicotomia contexto da descoberta/contexto da justificação, não está nem um pouco empenhado em zelar pela "integridade histórica" da ciência do passado. Refiro-me a ninguém menos que Paul Feyerabend. Com efeito, no sumário do capítulo IV de seu Contra o método, ele nos faz saber que "qualquer idéia, antiga e absurda, é capaz de aperfeiçoar nosso conhecimento. A ciência absorve toda a história do pensamento e a utiliza para o aprimoramento de cada teoria". Se é assim, e se o que está em discussão é a pertinência da dicotomia contexto da descoberta/contexto da justificação, então a questão é saber como a ciência "absorve a história do pensamento". Será que as práticas maquiavélicas, tão brilhantemente descritas por Feyerabend, têm al gum papel importante a desempenhar nesse processo? Para que a dicotomia possa ser afastada, a respos ta tem que ser um inequívoco "sim". Será essa a resposta de Feyerabend?

Para conhecer sua resposta basta ler sua iluminada réplica a uma objeção formulada por $\mathrm{M}$ ary $\mathrm{H}$ esse à sua tese. Essa tese, argumentou $\mathrm{H}$ esse, implica que até mesmo o mais bizarro sistema metafísico do passado pode ter deixado sua marca na ciência moderna. Se isso é verdade, então deveria ser proveitoso submeter tais sistemas à crítica; por exemplo, submeter à crítica a ciência moderna que estaria presente no aristotelismo ou, mesmo, no vodu. Como, continua H esse, uma crítica a tais corpos de conhecimento é inconcebível, é descabido supor que há algo desses corpos incorporado à ciência moderna.

A réplica de Feyerabend, arrisco dizer, mostra o quanto seu pensamento se manteve tributário tanto do pensamento popperiano como da dicotomia em discussão, apesar de seu hercúleo esforço para se livrar de ambos. Ela consiste simplesmente em mostrar que a crítica a corpos de conhecimento produzidos no passado está muito longe de ser, como supõe H esse, um exercício estéril. "M uitas vezes", diz Feyerabend, 
[...] obteve-se progresso graças a uma "crítica do passado", exatamente do tipo que H esse rejeita. D epois de Aristóteles e Ptolomeu, a idéia de que a terra se move estranha, antiga e "inteiramente ridícula" concepção pitagórica - foi jogada ao monte de entulhos da história, só vindo a ser revivida por Copérnico [...]. O s escritos mágicos desempenhavam importante papel nessa revivescência, ainda não perfeitamente compreendida, e foram estudados nada menos que pelo grande $\mathrm{N}$ ewton. Esses desenvolvimentos não surpreendem. Jamais se consegue estudar todas as ramificações de uma idéia e não há concepção a que se tenha dado a atenção por ela merecida. Teorias são substituídas por versões mais de acordo com as inclinações da época e são abandonadas muito antes de terem tido ocasião de exibir suas virtudes. Além disso, doutrinas antigas e mitos "primitivos" só se afiguram bizarros e desprovidos de sentido porque seu conteúdo científico ou não é conhecido ou éadulterado por filólogos e antropólogos não familiarizados com os mais simples conhecimentos físicos, médicos ou astronômicos. Vodu, a pièce de resistance da doutora $\mathrm{H}$ esse, é um caso em pauta. Ninguém o conhece e todos a ele se referem como um paradigma de atraso e confusão. Sem embargo, o vodu conta com uma base material firme, embora ainda não suficientemente comprendida, e um estudo de suas manifestações poderia enriquecer-nos e, talvez, levar-nos a rever nosso conhecimento acerca da fisiologia (1985, pp. 68-69).

Esse empenho em evitar que corpos de conhecimento do passado sejam jogados, sem mais, ao "monte de entulhos da história" - sem o qual, digase de passagem, nenhuma história da ciência pode merecer esse nome consiste, na minha opinião, no maior mérito de Feyerabend. $M$ as o que está na base desse empenho? Acredito que não seja outra coisa senão nossa velha dicotomia, da qual Feyerabend quer tão obstinadamente se livrar. Vejamos. Por que, segundo Feyerabend, o vodu deve ser estudado? Porque conta com uma "base material firme, ainda não suficientemente compreendida", ele responde. M esmo que essa "base material firme" não seja claramente definível, o próprio empenho em averiguar se algum corpo de conhecimento tem ou não essa característica diz respeito apenas ao contexto da justificação - pressupondo, dessa forma, a pertinência da dicotomia contexto da descoberta/contexto da justificação. Por que o vodu pode "levar-nos a rever nosso conhecimento acerca da fisiologia"? Feyerabend não responde, mas a resposta só pode ter a ver com a pressuposição, correta ou equivocada, de que o vodu, como corpo de conhecimento, encerra proposições que de al guma forma desafiam ou complementam, de um ponto de vista lógico, algumas das proposições do conhecimento fisiológico. U ma 
vez mais, o que quer que possa ocorrer no âmbito do "contexto da descoberta" é desdenhado. E o que dizer da afirmação de que "doutrinas antigas e mitos 'primitivos' só se afiguram bizarros e desprovidos de sentido porque seu conteúdo científico ou não éconhecido ou éadulterado por filólogos e antropólogos não familiarizados com os mais simples conhecimentos fís'cos, médicos ou astronômicos", ou ainda da afirmação, tão nitidamente passível de ser atribuída diretamente a Popper, de que "jamais se consegue estudar todas as ramificações de uma idéia e não há concepção a que se tenha dado a atenção por ela merecida"? Q ue luz o (correto) argumento de Feyerabend sobre o oportunismo maquiavélico inerente à prática científica pode lançar sobre 0 argumento apresentado em sua primorosa réplica a H esse? A dicotomia contexto da descoberta/contexto da justificação requer que a resposta seja um lacônico "nenhuma luz". Receio que a resposta seja exatamente essa. Como, então, evitar essa dicotomia, se ela está na base do louvável empenho de um de seus mais ferrenhos adversários em evitar que corpos de conhecimento produzidos no passado sejam impunementejogados ao "monte de entulhos da história"?

Em comparação com Feyerabend, Kuhn conseguiu manter-se afastado da referida dicotomia de forma mais consistente. N esse caso, entretanto, a coerência não parece ser uma vantagem. H á certos medicamentos cujo uso contínuo pode ocasionar algum desconforto mas, se os abandonarmos definitivamente, os efeitos serão ainda mais danosos. Em casos assim, não é vantajoso manter-se consistentemente afastado do medicamento. 0 mesmo, receio dizer, ocorre em relação à dicotomia contexto da descobertal contexto da justificação. Talvez possamos prescindir dela por algum tempo, mas chegará o momento em que os efeitos danosos se farão notar. U m delesé, como vimos, confinar por decreto todo equal quer corpo já desacre ditado de conhecimento ao "monte de entulhos da história". O utro, ainda mais danoso, esobre o qual ainda falarei, étornar o progresso científico um tema intratável. Feyerabend, por não ter se mantido tão coerente, conseguiu safar-se de ambos. Kuhn, mais coerente que Feyerabend, não se safou do primeiro. Felizmente, entretanto, sua coerência não chegou ao ponto de fazêlo calar-se sobre a natureza do progresso científico. Retorno a esse tema oportunamente. Por ora, discuto se al gum ganho pode advir do relativo sucesso de Kuhn em manter-se afastado da referida dicotomia. 


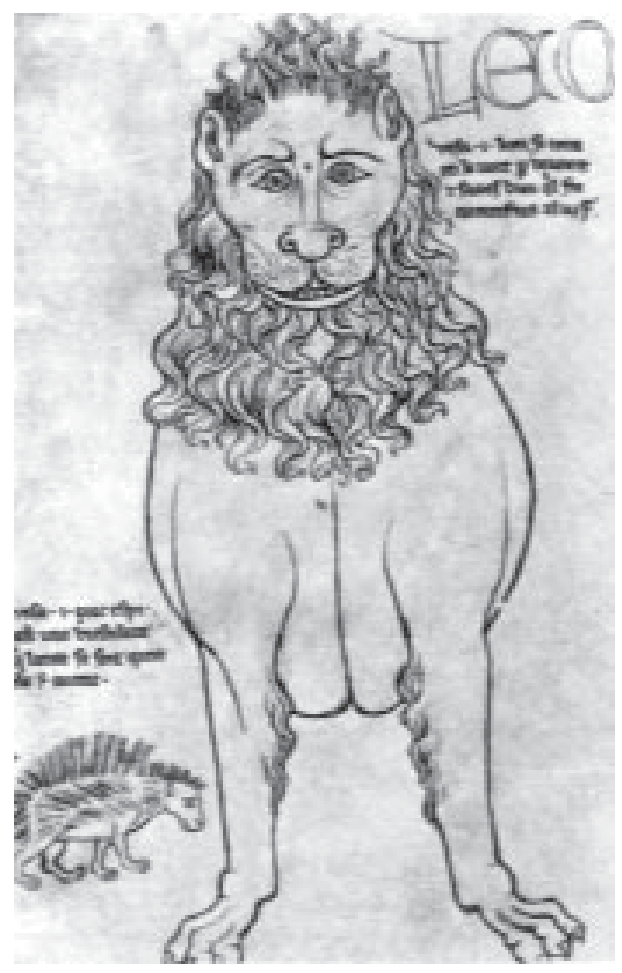

Fig. 1 Villard de Honnecourt, Lion et porcupine, c. 1235. Pena e tinta. Extraído de Gombrich (1995, p. 84).

Para empreender essa discussão, vou recorrer ao livro mais kuhniano que já tive a oportunidade de ler, o magnífico Arte eilusão de E. H . Gombrich, publicado pela primeira vez em 1957. Trata-se de uma obra anterior ao advento de Kuhn, e em cujo prefácio se lê: "sentir-meia orgulhoso se a influência do professor Popper fosse percebida por toda parte nesse livro" (G ombrich, 1995, p. XII). Para os propósitos da presente discussão, é suficiente mencionar que $G$ ombrich estava empenhado em entender o processo por meio do qual estilos de representação pictórica se formam e evoluem. O bserve-se, por exemplo, o quadro de um certo Villard de H onnecourt, datado de 1235 (Fig. 1). 0 leão ali retratado certamente parece ridículo. N os dias de hoje, até mesmo uma criança talentosa seria capaz de representar um leão de forma mais verossímil. Admitindo-se que Villard de $\mathrm{H}$ onnecourt tenha sido um artista de talento, e que tenha pretendido retratar fielmente um leão, por que uma representação pictórica tão pouco fiel a um "verdadeiro" leão? Seria pela indisponibilidade de leões reais que pudessem ser observados de forma mais detida, ou pela falta de um conhecimento mais acurado sobre como "de fato" um leão "é"? N ão, responde Gombrich, 


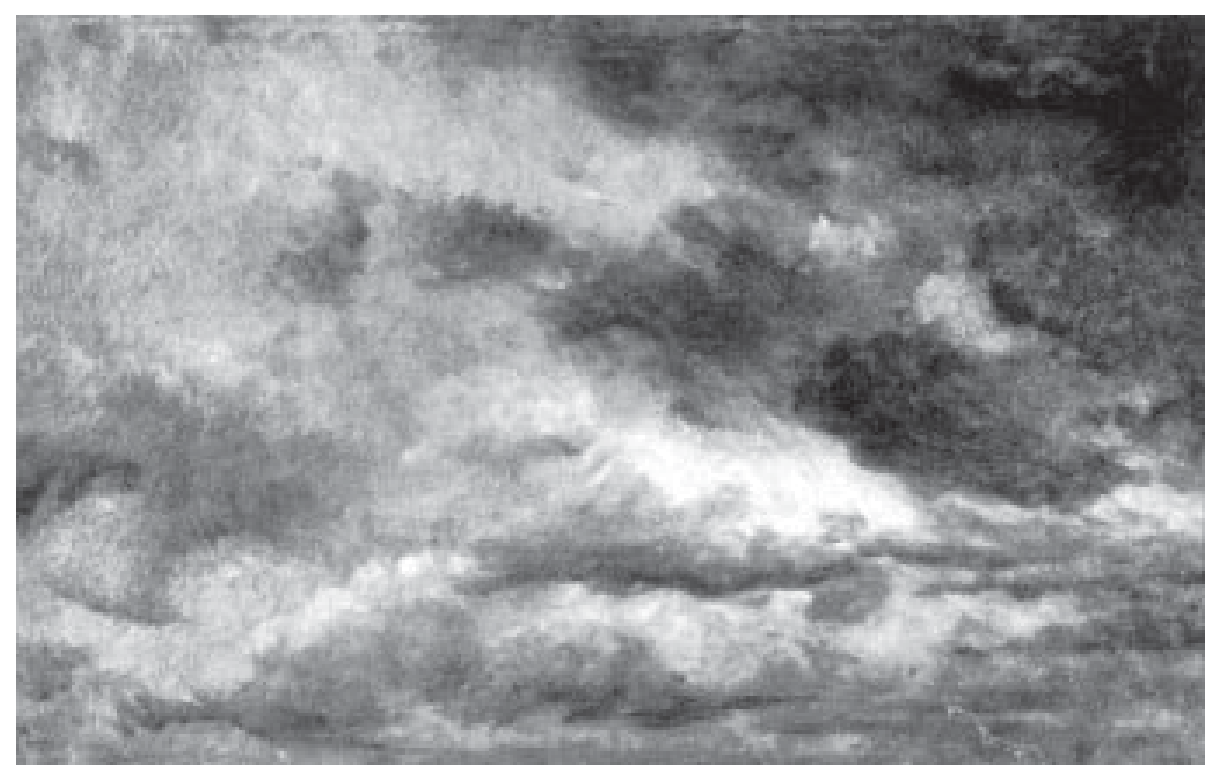

Fig. 2 Constable, Estudo de nuvens, 1822. Extraído de Gombrich (1995, p. 187).

isso tem a ver com a ausência de fórmulas ou modelos para pintar leões. Essas fórmulas são chamadas schematas. No século XIII, o repertório de schematas disponíveis para a representação pictórica de leões deveria ser muito pobre, daí, um "leão" tão inverossímil. Assim como para leões, pode haver schematas para mãos, pés, olhares tristes ou al egres, dias nublados e ensolarados etc.; sem um razoável repertório de schematas, um artista nada pode. D e onde vêm esses schematas? Freqüentemente de obras anteriores. U m quadro determinado representa pela primeira vez um raio rasgando 0 céu, o que proporciona material para a elaboração de vários schematas de raios, alguns dos quais serão aproveitados no futuro por outros artistas. $M$ as, e naquel as situações em que a função da arte não é a verossimil hança, como no caso das pinturas impressionistas? Para Gombrich, a única diferença é que, nesse caso, os schematas consistem basicamente em borrões de tinta. Se G ombrich pudesse viajar ao futuro e ler A estrutura das revoluções científicas, ele diria que na ausência de um repertório básico de schematas, com os quais os artistas pudessem contar e aos quais se sentissem obrigados a recorrer, o "resultado líquido" daquilo que porventura viessem a produzir seria "al go menos que arte".

Há, entretanto, uma diferença importante entre Kuhn e Gombrich. Gombrich pode documentar o modo como a arte depende de schematas de uma forma queKuhn não conseguiria documentar o modo como a ciência depende dos esquemas conceituais ${ }^{7}$ fornecidos pela educação profissional

7. "Q ualquer queseja o elemento dearbitrariedade contido em suas origens históricas e, ocasionalmente, no seu desenvolvimento posterior", conforme diz o próprio Kuhn (1982, pp. 23-24). 


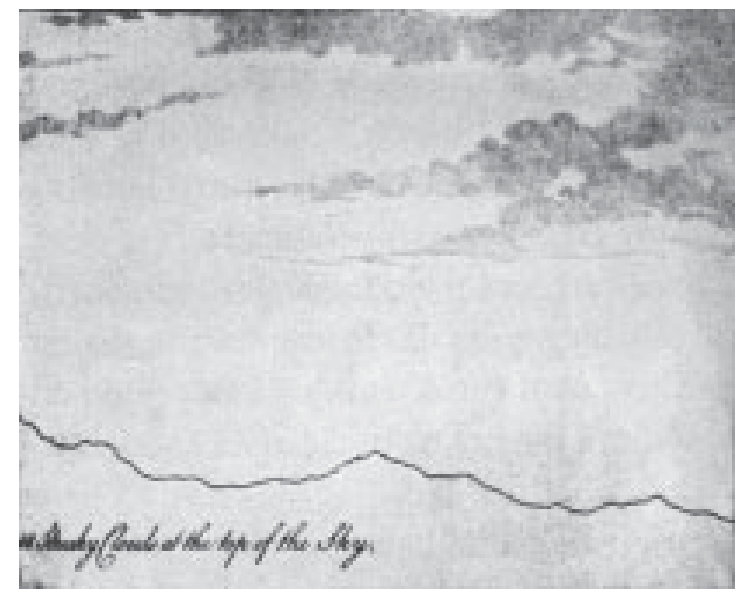

Fig. 3 Cozens, Modelo de céu, 1785.

Extraído de Gombrich (1995, p. 188).

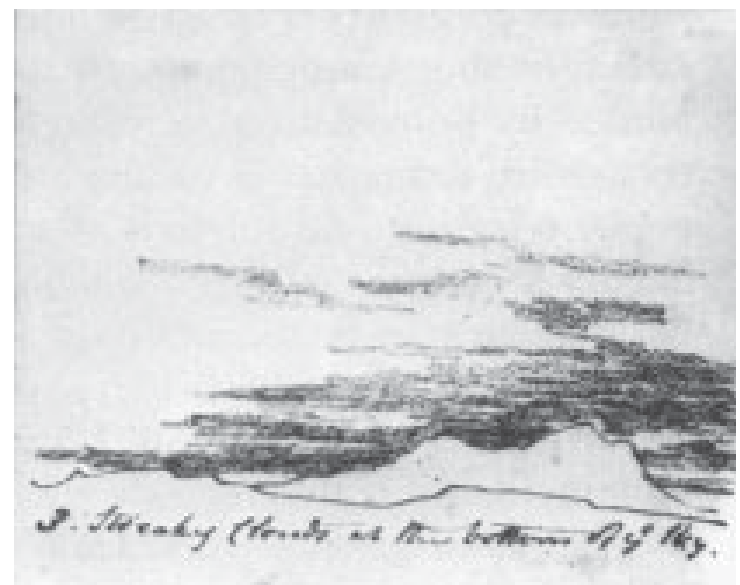

Fig. 4 Constable, Desenho segundo Cozens. Extraído de Gombrich (1995, p. 188).

do cientista. Curiosamente, quanto a esse ponto, Gombrich está em condição de ser mais kuhniano do que o próprio Kuhn. Considere-se, por exemplo, o belo quadro de John Constable(1776-1837), Estudo denuvens, datado de 1822 (Fig. 2). Gombrich mostra que essa obra não poderia ter sido produzida sem a prévia existência de schematas de nuvens, disponíveis somente a partir de 1785, em um livro de desenho de Alexander C ozens, um paisagista do século XVIII. Constable teve acesso ao livro e copiou alguns de seus schematas (Figs. 3 a 6), destinados a ensinar ao estudante de arte uma variedade de céus típicos: "nuvens esfiapadas no alto do céu" (Fig. 4); "nuvens esfiapadas muito baixas no céu" (Fig. 5); "metade nuvens, metade campo, as nuvens mais escuras que o campo ou dispersas pelo vento, emais escuras no alto que embaixo" (Fig. 6) - e assim por diante, com todo tipo de combinações e permutações. "Sabemos hoje", escreve G ombrich,

[... o o que C onstable aprendeu com C ozens. N ão foi, sem dúvida, a aparência das nuvens, mas uma série de possibilidades, ou schematas, que aprofundaram sua consciência delas através da classificação visual [... ]. Pouco importa que sistema de classificação adotamos. M as, sem alguns padrões de comparação, não podemos apreender a realidade. Tendo visto as criações de Constable, podemos também ver as nuvens de uma nova maneira (1995, pp. 188-189).

Pode haver algo mais kuhniano do que isso? 


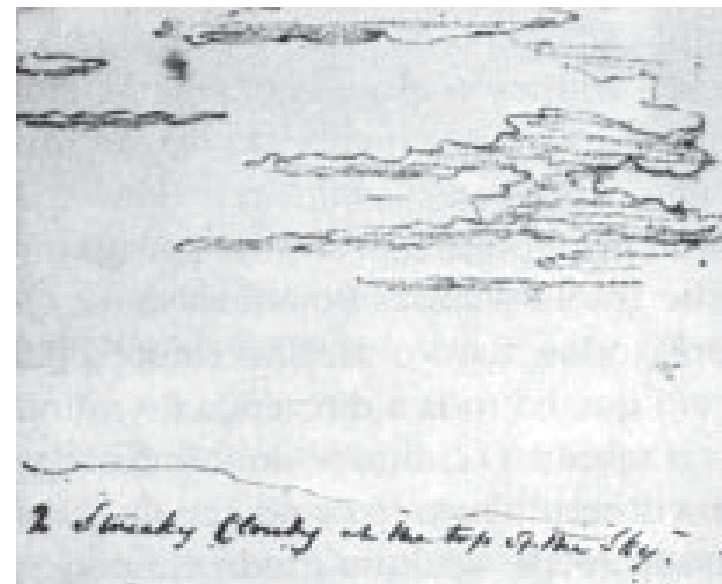

Fig. 5 Constable, Desenho segundo Cozens.

Extraído de Gombrich (1995, p. 188).

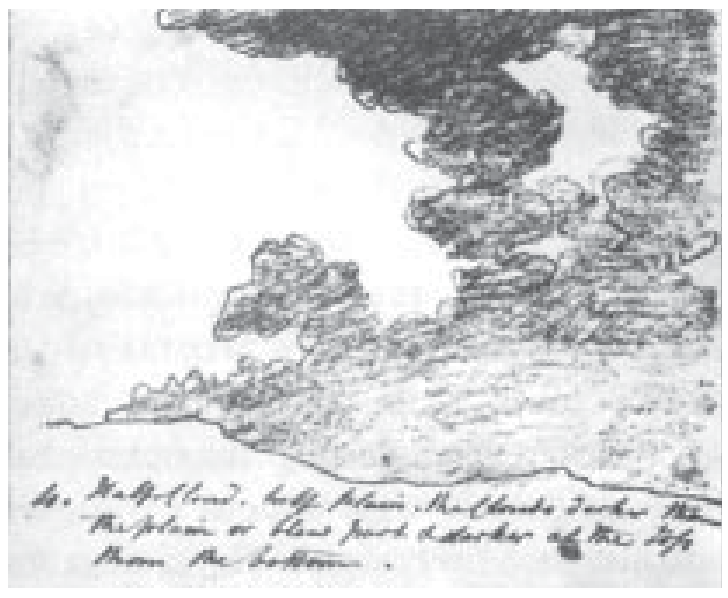

Fig. 6 Constable, Desenho segundo Cozens.

Extraído de Gombrich (1995, p. 188).

0 próprio Kuhn, entretanto, não pôde ser tão kuhniano porque não Ihe foi possível ir tão longe na demonstração - imprescindível, aliás, se se trata de dissolver a dicotomia contexto da descoberta/contexto da justificação - de como algo tão claramente passível de ser relegado ao domínio da história ou da sociopsicologia de um produto da atividade humana, seja ele a ciência, a arte, seja qualquer outro, pode ser tão inequivocamente responsável pelas características essenciais desse produto. Em outras palavras, Kuhn não pôde demonstrar que esquemas conceituais e modelos operacionais aprendidos no treinamento profissional do cientista respondem pelas características essenciais do conhecimento científico da mesma forma que Gombrich pôde demonstrar que schematas disponíveis em livros despretensiosos de desenho respondem pelas características essenciais dos diferentes estilos de representação pictórica.

É verdade que Kuhn procurou dar um passo nessa direção quando, ainda no primeiro capítulo de sua obra fundamental, sustentou que o empreendimento científico depende de obras paradigmáticas como a Física de Aristóteles, o Almageto de Ptolomeu, a Eletricidade de Franklin, a Q uímica de Lavoisier e a G eologia de Lyell, as quais, por encerrarem "realizações sem precedentes", estabelecem agendas específicas de investigação para "grupos duradouros" de praticantes (cf. Kuhn, 1982, p. 30). Mas dizer isso não é suficiente. Para se equiparar a G ombrich, Kuhn teria que mostrar que tais obras paradigmáticas têm certas características essenciais que, 
por sua vez, resultam de algo análogo aos schematas de nuvens, eles próprios disponibilizados por manuais despretensiosos. Em outras palavras, deveria ser possível mostrar que Ptolomeu, Franklin, Lavoisier, Lyell etc. tiveram seus respectivos Alexander Cozens, isto é, que algo teve, para 0 desenvolvimento das ciências de todos eles, a mesma importância decisiva dos schematas de que trata $\mathrm{G}$ ombrich para a evolução da arte.

Para melhor esclarecer esse ponto, retorno a Villard de H onnecourt. Vimos que para explicar por que seu "leão" (Fig. 1) é tão inverossímil se comparado a um "leão" dos nossos dias é necessário documentar os schematas de leão, ou de partes do leão, não disponíveis para al guém que, como Villard de Honnecourt, viveu no século XIII. Em A estrutura das revoluções científicas há uma passagem na qual Kuhn aparentemente faz algo análogo. Refiro-me à sua discussão sobre Aristóteles, G alileu e pedras oscilantes. D esde a Antigüidade remota, conta-nos Kuhn, muitas pessoas haviam visto um ou outro objeto pesado oscilando de um lado para o outro em uma corda ou corrente até chegar ao estado de repouso (Idem, p. 54). Para os aristotélicos, o corpo oscilante estava simplesmente tendo dificuldade em cair, por estar preso à corda, até atingir o repouso que, segundo eles, era o estado para o qual qualquer corpo naturalmente se dirige. Para Galileu, que havia rompido com a idéia de que o repouso fosse um estado mais "natural" que o movimento, tratava-se de um pêndulo, um corpo que por pouco não conseguia repetir indefinidamente o mesmo movimento. D e acordo com Kuhn, tal transição se deu porque $G$ alileu não recebeu uma formação totalmente aristotélica; ao contrário, foi treinado para analisar o movimento em termos da teoria do impetus, um paradigma do final da I dade M édia que tinha em $\mathrm{N}$ icolau $O$ resme, um escolástico do século XIV, um de seus mais expressivos teóricos. D e acordo com Kuhn, 0 resme esboçou uma análise da pedra oscilante que "é certamente muito próxima daquela utilizada por Galileu na sua abordagem do pêndulo" (I dem, p. 155). Admitindo-se que tudo isso seja verdade, o que Kuhn está nos dizendo? Por um lado, que há uma compatibilidade lógica entre as proposições que constituem a teoria do impetus e aquelas que constituem a abordagem do pêndulo de Galileu; por outro, que Galileu valeu-se da teoria do impetus para formular sua abordagem do pêndulo. A primeira afirmação diz respeito ao contexto da justificação; a segunda, ao contexto da descoberta. A dicotomia está mantida intacta. Para que fosse dissolvida em um caso como este, seria necessário que a teoria do impetus tivesse, na análise de Kuhn, um status análogo aos schematas como os das Figuras 3 a 6 . N os 
marcos detal analogia, a idéia de "corpo oscilantecom dificuldade em cair" corresponderia ao "leão" de Villard de H onnecourt, a idéia de "pêndulo" corresponderia a um "leão" mais verossímil ou, se se preferir, a um "leão" de qual quer outro estilo, e a teoria do impetus seria a responsável pela transição. M as a teoria do impetus, como de resto qualquer teoria, desfruta de uma integridade e de uma autonomia inexistente nos schematas. Teorias têm vida própria - como, aliás, mostrou esplendidamente Feyerabend em sua réplica popperiana a $\mathrm{H}$ esse. Elas podem ser testadas, ter suas ramificações investigadas, podem ser comparadas a outras teorias, evoluir a partir de confrontos etc., ao passo que tudo o que há para ser feito em relação a um pobre schemata, cujo caráter fragmentário, cabe acrescentar, contrasta radicalmente com o caráter íntegro de uma teoria, éusá-lo ou não para uma finalidade predeterminada. U m schemata desafia, portanto, a dicotomia contexto da descoberta/contexto da justificação de uma forma que nada do que Kuhn descreve em sua obra o faz. 0 fato de ser possível mostrar sua importância decisiva para a emergência de um determinado estilo de representação pictórica, à margem de qualquer consideração sobre as contingências sócio-históricas em que ele (o schemata) foi concebido, o livra de ser relegado ao contexto da descoberta. Aliás, abrindo um parêntese, não é por outra razão que, ao documentarmos os schematas imprescindíveis para a produção de uma obra de arte, estamos fazen do muito mais que uma mera crônica da arte: estamos explicando não só a existência de estilos mas também as diferenças entre eles. Por outro lado, o fato de um schemata não ser um corpo íntegro de conhecimento, com vida própria, cujas proposições possam ser relacionadas umas com as outras e com proposições oriundas de outros corpos de conhecimento, impede sua inserção no "contexto da justificação".

Resta saber se o fato de Kuhn não ter ido tão longe em sua tentativa de trazer para a filosofia da ciência aquilo que a dicotomia contexto da descoberta/contexto da justificação afirma ser tratável apenas em termos sociopsicológicos (ou sócio-históricos), a saber, o próprio processo de geração de teorias, deve-se a uma deficiência, corrigível, de sua filosofia da ciência ou se é porque, tendo lidado com ciência e não com arte, ele realmente não poderia ter ido mais longe. $\mathrm{H}$ averá algo (documentável) tão decisivo para a determinação dos traços essenciais de uma dada teoria quanto os schematas representados nas Figuras 3 a 6 o foram para a determinação do estilo de Constable? D esconheço a resposta, mas Kuhn teve que apostar que sim. $\mathrm{N}$ a impossibilidade de identificar al go que pudesse corresponder aos schematas, Kuhn teve que arriscar afirmações como "não pode haver 
ciência sem um conjunto-padrão de métodos ou de fenômenos que toda uma geração de estudiosos se sinta forçada a empregar e a explicar", ou

[...] a pesquisa eficaz raramente começa antes que uma comunidade científica pense ter adquirido respostas seguras para perguntas como: quais são as entidades fundamentais que compõem o universo? Como interagem essas entidades umas com as outras e com os sentidos? Q ue questões podem ser legitimamente feitas a respeito de tais entidades e que técnicas podem ser empregadas na busca de soluções? (1982, p. 23).

Entretanto, ainda que se dê corpo a tudo isso, investigando o modo como certos "conjuntos-padrões de métodos" ecertas respostas a perguntas como as que Kuhn tão pertinentemente listou são fundamentais para 0 estabelecimento de certas disciplinas científicas, o resultado, por tudo 0 que expus anteriormente, ainda será pobre se comparado ao obtido por Gombrich ao mostrar o modo como schematas determinados são direta-

8.A propósito, Kuhn parecia conhecer bem a referida obra de Gombrich, pois se vale dela em sua obra para traçar paralelos entre a arte e a ciência.

9. Agradeço ao professor Paulo Abrantes, do Departamento deFilosofia da Universidade deBrasília, por ter chamado minha atenção para isso. mente responsáveis pelo que há de di stintivo nos diferentes estilos de representação pictóricå.

M as admitamos que essa desvantagem de Kuhn em relação a Gombrich seja apenas uma lacuna, provisória, de sua filosofia da ciência. N esse caso, haveria algo, análogo aos schematas, passível de ser documentado e incorporado à filosofia da ciência e, com isso, a pertinência da dicotomia contexto da descoberta/contexto da justificação estaria realmente em questão. N ão descarto a possibilidade de que tal incorporação possa ocorrer, mesmo porque existem trabal hos nessa direção ${ }^{9}$, mas devo chamar a atenção para 0 fato de que, mesmo nesse caso, a rejeição à dicotomia não poderia ser feita impunemente por muito tempo. N os capítulos finais de sua obra, Kuhn advoga tal rejeição não só porque entende que a referida dicotomia inviabiliza um entendimento adequado do processo pelo qual a ciência realmente progride, mas, sobretudo, porque entende que a dicotomia mascara o fato de que "progresso científico", agora entre aspas, é apenas o resultado de uma maneira peculiar de contar a história da ciência.

M as é possível falar em progresso científico, com ou sem aspas, sem se comprometer, irremediavelmente, com a dicotomia contexto da descoberta/contexto da justificação? Receio que não. Perguntar se e como a ciência progride envolve sobretudo perguntar see por que uma determinada teoria representa um ganho de conhecimento em relação a uma teoria anterior, e tal indagação só concerne ao contexto da justificação. Ela separa este últi- 
mo do contexto da descoberta da mesma forma que uma centrífuga separa um líquido dos sedimentos nele contidos. A única maneira de dissolver a citada dicotomia é, então, evadir a tal indagação. É silenciar sobre o progresso da ciência. O s sociólogos e os historiadores da ciência pós-kuhnianos, o que inclui a voga recente de estudos etnográficos sobre a ciência, 0 fizeram e não conseguiram produzir mais que uma insossa crônica da ciência - conforme pretendo ainda mostrar. Felizmente, nem Feyerabend nem Kuhn optaram pela evasão - nenhum deles, afortunadamente, conseguiu ser coerente a ponto de permitir que a rejeição da dicotomia os conduzisse a isso. Ambos reservaram para a referida indagação um papel crucial em seus respectivos pensamentos. No caso de Feyerabend, isso se torna claro quando ele se empenha em mostrar, conforme vimos, a importância de corpos de conhecimento produzidos no passado para o desenvolvimento de corpos de conhecimento produzidos em um tempo posterior. No caso de Kuhn, isso se torna claro quando el e se empenha em explicar a importância de teorias ainda não devidamente articuladas para o progresso da ciência. $\mathrm{N}$ a medida em que Kuhn e Feyerabend se envolveram com tais reflexões, de cunho nitidamente epistemológico, e em que, se não o fizessem, veriam seus respectivos argumentos sobre o caráter sócio-histórico do empreendimento científico reduzidos a uma mera crônica da ciência, ambos se revelaram profundamente tributários da dicotomia que tão obstinadamente buscaram dissolver.

Tendo se movido inteiramente à margem de toda essa discussão, seja por mero desconhecimento, seja por suporem, um tanto ingenuamente, que os esforços de Kuhn e/ou Feyerabend haviam sido suficientes para liquidar de vez o assunto, os etnógrafos da ciência se sentiram à vontade para se dedicar à science-in-the-making, cujo resultado podemos agora avaliar. Acredito que o foco na science in-the making conduziu a três teses, a saber:

- Na comunidade científica, o consenso não brota espontaneamente de testes cruciais ou de debates críticos. Aquilo que os livros-textos de ciência e/ou os artigos científicos apresentam como "corroboração experimental", "refutação de uma teoria", "descoberta científica" etc. é, sobretudo, o resultado de árduas negociações nas quais considerações de ordem racional nem sempre cumprem um papel importante. 
10. Tanto quanto a ciência, a religião procura oferecer respostas para problemas determinados. Toda religião procura, sobretudo, explicar a relação entre mé rito e destino. D e acordo com $M$ axWeber, todas as grandes religiões que hoje conhecemos venceram, em algum momento do passado, uma acirrada disputa contra alguma religião alternativa- queacabou por se extinguir. Para tanto, elascontaram com a sua capacidade de explicar o infortúnio mas, sobretudo, com a existência de segmentos sociais interessados em difundir suas doutrinas por toda uma civiliza ção. Assim, uma casta deletradoscultosdifundiu o hinduísmo, o budismo foi propagado pe los monges e o islamismo pelosguerreiros. $\mathrm{Re}$ ligiões que não conse guiram encontrar "portadores" suficientemente robustos acabaram por extinguir-se. Para não ser trivial, a primeira tese teria que implicar uma expansão detal raciocínio para a ciência, no sentido deapontar alguma ciência que veio a ser extinta em razão denão encontrar "portadores" no interior
- M étodos igualmente aceitos como "científicos" podem conduzir a re sultados diferentes ou mesmo incompatíveis. $\mathrm{H}$ arry Collins elaborou este ponto de forma bastante obscura ao afirmar que sua sociologia do conhecimento científico representa um esforço pioneiro no sentido de mostrar que "sob determinadas circunstâncias sociais, o 'método científico correto', aplicado a um determinado problema, gera o resultado $p$, ao passo que sob outras circunstâncias sociais o 'método científico correto', aplicado ao mesmo problema, gera o resultado $q$, onde talvez $q$ implica não-p" (1982, p. 302).

- Todo conhecimento, incluindo o científico, emana da construção e do uso de "caixas-pretas", isto é, de esforços no sentido de tornar uma alegação de conhecimento invulnerável a questionamentos posteriores e, em conseqüência, o que há de fundamental para ser investigado a respeito da ciência é o modo como determinadas "caixas-pretas" são construídas, usadas e, eventualmente, abertas e substituídas.

$\mathrm{N}$ ão tenho muito a dizer sobre as duas primeiras teses. A primeira é um legado direto dos esforços empreendidos por Kuhn para mostrar a permeabilidade do conhecimento científico a contingências de caráter sócio-histórico. Se decisões contingentes e compromissos assumidos no interior da comunidade científica fazem parte da natureza do conhecimento científico, e se ambos poderiam ter sido outros se as circunstâncias históricas e sociais nas quais as comunidades científicas se estabeleceram e se desenvolveram tivessem sido outras, então somos levados a concluir que o conhecimento científico, tal como hoje o conhecemos, poderia ter sido outro. 0 ra, se isso é verdade, então deve haver uma ciência alternativa. No mínimo, deve haver algum registro de alguma física, química ou biologia alternativa que em algum momento do passado tenha sido extinta por razões de ordem sociológica da mesma forma que há registros de religiões que se extinguiram por razões de ordem sociológica ${ }^{10}$. Q ue ciência alternativa é essa? Enquanto essa pergunta não for respondida, a primeira tese não faz mais que repetir aquilo que a dicotomia contexto da descoberta/contexto da justificação assevera: que o comportamento efetivo dos cientistas, incluindo a maneira como produzem seus trabalhos e decidem sobre o que aceitar como um "fato", um "erro", ou o que quer que seja, é um tema a ser tratado em termos sociopsicológicos. A segunda tese, ainda mais trivial, limita-se a repetir algo que pelo menos desde Popper éamplamente sabido: quea ciência não dispõe de um método capaz de garantir, de antemão, a validade de seus resultados. 
A terceira tese é a coluna vertebral da etnografia da ciência de Bruno Latour. D etive-me nela em outras oportunidades (cf. Freitas, 1998; 2000), sem, entretanto, ter mostrado como sua "condição de possibilidade" éjustamente 0 ato, talvez deliberado, de ignorar a existência do debate sobre a pertinência da dicotomia contexto da descoberta/contexto da justificação. Faço-o agora, então, val endo-medo trabal ho deSimon Schwartzman (1997), "O s dinossauros de Roraima"11, que mostra com excepcional clareza o quanto uma etnografia da ciência pode ressentir de tal ato.

N esse artigo, Schwartzman comenta um livro de Latour intitulado La clef de Berlin et autres leçons d'un amateur de sciences, publicado em 1993. Latour esteve em Roraima em 1991 e acompanhou de perto o trabalho de pesquisadores franceses e brasileiros que queriam entender como se dá a interação entre a savana e a floresta em uma região em que os dois ambientes se encontram. É a savana que avança sobre a floresta ou, ao contrário, é a floresta que avança sobre a savana? Isso, afirma Schwartzman, interessava aos geógrafos e botânicos, mas não, evidentemente, a Latour, que

[...] anos antes, havia inaugurado a tradição, tantas vezes repetida depois, de acompanhar o trabalho dos cientistas com os mesmos olhos que os antropólogos acompa nhavam a vida dos indígenas, em um efforço de construir uma interpretação da realidade que pudesse ir além dos mitos e representações correntes, seja dos pesquisadores, seja dos pesquisados. A "antropologia da ciência" ajudou a romper as barreiras que tanto a epistemologia quanto a sociologia tradicionais haviam erigido entre o mundo social, carregado de valores, conflitos, mitos e imprecisões, eo mundo da ciência, idea lizado como o reino da lógica, da razão, da técnica e da eficiência (1997, pp. 69-70).

N essa passagem, Schwartzman dá a entender que a epistemologia "tradicional" concebe o empreendimento científico como algo isento de "valores, conflitos, mitos e imprecisões". Ele é um pouco vago sobre a epistemologia da qual está falando, mas certamente não é a que se desenvolveu no século XX. Esta, de fato, "erigiu uma barreira", mas não foi, como ele afirma, entre o mundo social e o mundo da ciência, mas entre aquilo que, no que concerne ao conhecimento científico, é tratável em termos estritamente lógicos e aquilo que não o é. O s meios de testar uma teoria, sua compatibilidade ou incompatibilidade com outras, o que ela representa em termos de avanço do conhecimento, são temas pertinentes à primeira categoria, constituindo, conforme já vimos, o que se convencionou chamar de "contexto da justificação". As origens históricas, a gênese e o de da comunidade científica. Teria que mostrar, por exemplo, que houve alguma física alternativaàfísicanewtoniana que só não prosperou porquenão encontrou, na comunidade científica, grupos interessadosem, esuficientementepoderosos para, propagá-la.

11. Publicado originalmente em N ovos Estudos Cebrap, 39: 172179, jul. 1994. 
12.Vali-me aqui dos termosdeH erbertFeigl (apud Feyerabend, 1985, pp. 259-260). senvolvimento psicológicos e as condições sociopolítico-econômicas para a aceitação ou rejeição de teorias ${ }^{12}$ são temas pertinentes à segunda, e só podem ser tratados por alguma disciplina empírica, seja a sociologia, a psicologia, seja a história. Esses temas, como já vimos, pertencem ao que se convencionou chamar "contexto da descoberta".

Aquele que não se tenha furtado a refletir sobre as implicações de tal distinção perceberá prontamente que nada há de surpreendente em uma constatação como a seguinte:

[...] vista nos seus quefazeres cotidianos, a pesquisa científica não énem mais nem menos "racional" do que qualquer outra atividade humana, os conhecimentos obtidos não derivam de uma lógica ou razão atemporais, nem de generalizações e abstrações obtidas diretamente da observação sistemática dos fatos. Eles surgem como construções provisórias e tentativas, desenvolvidas em um processo gradual de decisões oportunistas, negociaç̃eses em muitos casos, a imposição dos pontos de vista de uns sobre os demais (Schwartzman, 1997, p. 70).

Q ue os etnógrafos da ciência queiram documentar as "construções provisórias e tentativas" envolvidas nos "quefazeres cotidianos" da pesquisa científica éal go contra o qual não posso me opor. M as eles deveriam descobrir 0 que fazer a partir daí. 0 que a passagem de Schwartzman citada assevera não é outra coisa que a mais óbvia das implicações da dicotomia contexto da descoberta/contexto da justificação: no âmbito dos "quefazeres cotidianos" da pesquisa científica, isto é, do que concerne ao "contexto da descoberta", tudo pode acontecer. Resultaria daí que o empenho em investigar os "quefazeres cotidianos" da pesquisa científica é de todo inútil? N ão necessariamente, mas, como procurei mostrar na seção anterior, não vislumbro outra maneira de extrair algo não trivial de tal investigação a não ser documentando o que possa porventura cumprir, no empreendimento científico, um papel análogo ao dos schematas na arte.

$\mathrm{N}$ a impossibilidade de documentar algo de tal relevância, a etnografia de Latour passa, por assim dizer, a atirar a esmo. É o que Schwartzman, ainda que involuntariamente, nos mostra em seu artigo. Ele explora algumas das direções nas quais Latour atira. Para os propósitos da presente discussão, é suficiente deter-me em uma delas, a que o próprio Latour chamou de "montagem foto-filosófica", apresentada em um ensaio intitulado "Le 'pédofil' de Boa Vista: montage photo-philosophique" (cf. Schwartzman, 1997, p. 70). A primeira fotografia desse ensaio, conta-nos Schwartzman, é 
[...] de um ponto de encontro da savana com a floresta - situação única, perdida nas profundezas de Roraima, longe dos homens e da civilização. A última é do pesquisador em seu escritório, escrevendo em seu notebook um artigo sobre os resultados da pesquisa, baseado em um gráfico que resume, em uma página, toda a riqueza e variedade da botânica e do solo na região pesquisada, em termos que possam ser entendidos universalmente pelos interessados nos problemas de transição e transformação ambientais (Idem, pp. 70-71).

A conclusão da pesquisa, informa Schwartzman em uma desdenhosa nota de rodapé, é a de que é a floresta que avança, graças à ação das minhocas, que vão transformando o solo arenoso da savana em um solo argiloso-arenoso, mais propício à vegetação densa.

D adas essas informações básicas, é chegado o momento de a "montagem foto-filosófica" mostrar a que vem:

Entre os dois extremos, uma fotografia crucial, a do pesquisador que, com uma mão, pega um pedaço de terra e, com a outra, o coloca em uma caixa quadriculada que classifica as amostras do solo por sua posição e profundidade. É isto, diz Latour, o que significa abstrair: transformar um objeto concreto, único, local e insubstituível em um elemento de um conjunto maior, dentro de uma classificação por cores e posições. Em filosofia da ciência, observa ele, a mão direita ignora o que faz a mão esquerda, mas a observação antropológica desfaz esse mistério: 0 pesquisador não vai de um solo particular a uma I déia ou conceito abstrato de solo, mas de um pedaço de terra contínuo e multíplice a uma cor discreta em um conjunto geométrico codificado por uma abscissa e uma ordenada. É por sucessivas transfor maçoes como essas que o conhecimento científico avança. 0 queél local, particular, material, múltiplo e contínuo vai perdendo especificidade ao ser comparado, estandardizado, calculado, transformado em texto, comunicado, universalizado. É um processo duplo de redução, a floresta e a savana que agora cabem em um artigo científico, e de ampliação, uma realidade local e irrepetível que agora faz parte de um universo amplo de conhecimentos e relações (Idem, p. 71).

Se Gombrich se empenhou em documentar os schematas responsáveis por nada menos que a existência de estilos e a evolução da representação pictórica na arte, Latour está interessado em documentar, conforme nos mostra Schwartzman, as "sucessivas transformações" por meio das quais o "que é local, particular, múltiplo e contínuo vai perdendo especificidade ao ser comparado, estandardizado, calculado, transformado em texto, co- 
municado e universalizado". Espero, a essas alturas, ter deixado claro qual a relevância de documentar os schematas. M as o que dizer da relevância de documentar as "transformações sucessivas" a que Schwartzman se refere? Realcei, na citação acima, a resposta que Schwartzman oferece: o conhecimento de tais tran fformações, ele diz, são relevantes porqueexplicam o modo como o conhecimento científico avança. M as essa não me parece uma boa resposta. Latour limitou-se a documentar alguns dos modos pelos quais os cientistas são bem-sucedidosem elaborar suas síntesese comunicá-las a quem quer que possa se interessar por elas. $D$ aí a dizer algo proveitoso sobre 0 avanço do conhecimento científico vai uma enorme distância, e Latour, como pretendo argumentar, não deu um passo sequer em tal direção.

Para saber se da pesquisa realizada em Roraima resultou ou não algum avanço de conhecimento seria imprescindível averiguar as implicações, no que concerneao conhecimento sobre transição etransformação ambientais, das conclusões dessa pesquisa. Afinal, dizer que há algum avanço de conhecimento envolve dizer que de al guma maneira novos problemas emergiram ou estão emergindo e novas áreas de investigação se abriram ou estão se abrindo. Admitamos, com Schwartzman, que a síntese a que os pesquisadores chegaram, e o modo como a comunicaram, foi resultado das "transformações sucessivas" que ele tão bem descreveu. M uito bem, o que resultou a partir daí? Alguma nova área de investigação se abriu? N ovos problemas emergiram e/ou o estado do conhecimento sobre transição e transformação ambientais foi, de alguma forma, revisto e/ ou ampliado? Se a resposta a al guma dessas perguntas for sim, então a pesquisa em Roraima, tão laboriosamente acompanhada por Latour, de fato representou algum avanço de conhecimento. N esse caso, para que a "montagem foto-filosófica" tenha alguma relevância, deve ser possível mostrar que as "transformações sucessivas" que ela registrou foram decisivas não apenas para a produção e ampla divulgação de um sintético artigo científico, como sugere Schwartzman, mas também para que tal artigo produzisse desdobramentos (suscitar novos problemas, ampliar o estado do conhecimento sobre transições ambientais) dignos de nota. $\mathrm{N}$ ão espanta que Latour não tenha caminhado um milímetro sequer nessa direção, pois para isso ele teria que fazer o que nenhum etnólogo (ou antropólogo) da ciência pode fazer: investigar, por um lado, os desdobramentos do artigo científico cujo processo de produção ele documentou e, por outro, a relevância de tudo que foi documentado para 0 entendimento dos desdobramentos do artigo. Se, por outro lado, a resposta for não, então todo o esforço dos botânicos e geógra- 
fos que Latour acompanhou foi inútil: a conclusão de que é a floresta que avança devido à ação das minhocas - ela própria só tornada possível, admitamos, por ter envolvido o processo de abstração que Latour considerou tão crucial analisar - não passaria de uma mera curiosidade. N esse caso, todo o empenho de Latour em documentar as "transformações sucessivas" a que se refere Schwartzman teria sido também inútil: afinal, qual é 0 sentido de documentar o que está envolvido em uma atividade dita científica cujo resultado final não é cientificamente relevante ${ }^{13}$ ? Em termos mais gerais, se uma mesma prática - por exemplo, o processo por meio do qual os cientistas fazem suas abstrações - pode conduzir tanto a resultados significativos do ponto de vista do avanço do conhecimento científico quanto a meras curiosidades, o que pode resultar do empenho em documentar essa prática além de uma mera crônica da ciência? Se Latour tivesse encarado seriamente, como Kuhn e Feyerabend, as implicações da dicotomia contexto da descoberta/contexto da justificação, teria concluído que é por considerar inútil a análise de qualquer processo concernente ao empreendimento científico sem uma prévia reflexão a respeito da relevância científica do resultado desse processo (e não por perversamente erigir uma barreira entre o mundo social e o mundo da ciência) que a filosofia da ciência desdenha aquilo a que ele próprio atribui tanta importância: 0 exame das transformações sucessivas por meio das quais o processo de abstração se dá, ou, para retomar as palavras de Schwartzman, o processo por meio do qual algo como "um ponto de encontro da savana com a floresta - situação única, perdida nas profundezas de Roraima, longe dos homens e da civilização" - é convertido em um artigo no qual um único gráfico resume, em uma única página, "toda a riqueza e variedade da botânica e do solo na região pesquisada, em termos que possam ser entendidos universalmente pelos interessados nos problemas de transição e tran sformação ambientais" (Schwartzman, 1997, pp. 70-71).

A natureza de minha objeção pode tornar-se mais clara se imaginarmos um Gombrich que se pusesse a documentar o processo de produção de certas obras de arte sem se preocupar em mostrar quehá al go peculiar a esse processo - no caso, a utilização de schematas - , sem o qual nada digno de nota (um determinado estilo, por exemplo) pode ser estabelecido na arte. U m Gombrich assim poderia até escrever um volumoso tratado sobre a arte, mas que seria tão lacunar que, ao fim da leitura das detal hadas descrições ali contidas, o leitor sentir-seia profundamente frustrado por nada ter aprendido a respeito do modo como os mais diferentes estilos de represen-
13. Cabe aqui uma qual ificação para evitar mal-entendidos، "Cientificamente relevante" não ésinônimo de "correto", nem de "bem-sucedido" ou "vencedor" (no sentido de bemaceito pela comunidade científica). Conforme vimos na seção anterior, atéo vodu pode, em princípio, ser cientificamente relevante. 
tação pictórica se estabelecem e evoluem. Receio que esse G ombrich mutilado, que acabo de inventar, seja o protótipo do etnógrafo da ciência. Afinal, trata-se de um estudioso da arte que, se um dia viesse a se interessar por ciência, pôr-seia a atirar a esmo, documentando toda sorte de práticas científicas, sem perceber que éimprescindível identificar o que há de peculiar a elas, que as tornam indispensáveis para que al go digno de nota, como a emergência de um novo problema e/ou a revisão de um determinado estado de conhecimento, venha a acontecer na ciência.

Referências Bibliográficas

Collins, H . (1982), "Knowledge, norms and rules in the sociology of science". Social Studies of Science, 12: 299-309. . (1992). Changing O rder. Chicago, The University of Chicago Press.

Feyerabend, Paul. (1985), Contra o método. Rio de Janeiro, Francisco Alves.

FreITAS, Renan Springer de. (1998), "Em busca da sociologia não paroquial". Revista Brasileira de Ciências Sociais, 13 (38): 137-150. . (2000), "A desforra de H ume". Revista Brasileira de Ciências Sociais, 15 (42): 23-38.

. (2004), "A saga do ideal de boa ciência". Revista Brasileira de Ciências Sociais, 19 (55): 91-105.

Gombrich, E. H . (1995), Arte e ilusão. São Paulo, M artins Fontes. H oyningen -H uene, P. (1987), "On the varieties of the distinction between the context of discovery and the context of justification". Studies in History and Philosophy of Science, 18: 501-515.

Kunn, Thomas. (1982), A estrutura das revoluçoes científicas. São Paulo, Perspectiva. Schwartzman, S. (1997), A redescoberta da cultura. São Paulo, Edusp. Publicado originalmente em N ovos Estudos Cebrap, 39:172-179, jul. 1994

Zimmerman, D. \& Pollner, M. (1970), "The everyday world as a phenomenon". In Douglas, J. (ed.). Understanding Everyday Life. Chicago, Aldine. 


\section{Resumo}

A sedução da etnografia da ciência

Este artigo compara os resultados do exercício, peculiar aos sociólogos e antropólogos da ciência pós-kuhnianos, de documentar a prática científica cotidiana - ou o que se convencionou chamar de science-in-the-making - com os resultados advindos de um exercício análogo, relativo à arte, realizado al gumas décadas antes pelo historiador da arte Ernst Gombrich. Argumenta-se que, enquanto Gombrich foi conduzido a resultados verdadeiramente auspiciosos - sendo-Ihe permitido, por meio de seu empenho em estudar o que se poderia chamar de art-in-themaking, mostrar como diferentes estilos de representação pictórica se formam e evoluem - , sociólogos e antropólogos pós-kuhnianos foram conduzidos a apenas uma insossa crônica da ciência. D iscute-se a razão do sucesso do primeiro e do fracasso dos últimos.

Palavras-chave: Etnografia da ciência; Progresso científico; Contexto da descoberta; Contexto da justificação; Schemata.

\section{Abstract}

The lure of ethnography of science

This articles compares the results which have come out of the exercise, peculiar to post-Kuhnian sociologists and anthropologists of science, of documenting everyday scientific practices - or what has been called "science-in-the-making" - with the re sults which came out of an analogous exercise, concerning art, undertook some decades earlier by the art historian Ernst $\mathrm{G}$ ombrich. I argue that whereas $\mathrm{G}$ ombrich was led to very auspicious results - his concern with what could be called "art-in-themaking" has allowed him to explain how different styles of pictorial representation are formed and how they evolve-, the post-kuhnian sociologists and anthropologists were led to nothing but a tasteless chronicle of science. I discuss the reason of both, the success of the first and the failure of the latter.

Keywords: Ethnography of science; Scientific progress; C ontext of discovery; Context of justification; Schemata.

Texto recebido em $3 /$ $3 / 2003$ e aprovado em $3 / 12 / 2004$.

Renan Springer deFreitas é professor do D epartamento de Sociologia e AntropologiadaU FM G. E-mail: springer@netu no.lcc.ufmg.br 